2019

\title{
Investigating the management of alcohol-related presentations in an Australian teaching hospital
}

Siyu Qian

University of Wollongong, Illawarra and Shoalhaven Local Health District, sqian@uow.edu.au

Mudar Irani

Illawarra Shoalhaven Local Health District

Renee M. Brighton

University of Wollongong, reneeb@uow.edu.au

Wilfred W. Yeo

University of Wollongong, Illawarra Shoalhaven Local Health District, wilf@uow.edu.au

David Reid

Illawarra Shoalhaven Local Health District, Drug And Alcohol Service

See next page for additional authors

\section{Publication Details}

Qian, S., Irani, M., Brighton, R., Yeo, W., Reid, D., Sinclair, B., Bresnahan, S., Lynch, P., Feng, X. \& Yu, P. (2019). Investigating the management of alcohol-related presentations in an Australian teaching hospital. Drug and Alcohol Review, 38 (2), 190-197.

Research Online is the open access institutional repository for the University of Wollongong. For further information contact the UOW Library: research-pubs@uow.edu.au 


\title{
Investigating the management of alcohol-related presentations in an Australian teaching hospital
}

\author{
Abstract \\ Introduction and Aims: Alcohol-related morbidity is estimated to range from $10-38 \%$ of the presentations to \\ hospital emergency departments. This study aims to investigate the actual management process for \\ alcohol-related presentations in a teaching hospital in Australia.
}

Design and Methods: Retrospective audit was conducted on the electronic medical records of 210 presentations with a primary or secondary diagnosis of 'alcohol use disorder' at discharge between November 2016 and February 2017. Six key management steps were investigated: identification of alcohol use disorder, documentation, thiamine, alcohol withdrawal assessment, benzodiazepine for alcohol withdrawal and referral to the drug and alcohol consultation liaison service.

Results: Of all the 210 presentations, $77.1 \%$ (162) were identified with alcohol use disorder in the initial assessments; 64.3\% (135) were documented with alcohol use history, 49.5\% (104) were prescribed with thiamine, $48.1 \%$ (101) were assessed with the alcohol withdrawal scale, $41 \%$ (86) were prescribed with benzodiazepine for alcohol withdrawal and only 38.6\% (81) were referred to the drug and alcohol consultation liaison service. Only $8.6 \%$ (18) of the initial presentations were directly related to alcohol. These presentations had a higher completion rate in each of the six steps than those $(91.4 \%, 192)$ not directly related to alcohol. Only $6.2 \%$ (13) were formally screened for alcohol use.

Discussion and Conclusions: The findings suggest a need to improve the alcohol management practice in the hospital. Routine use of an alcohol screening tool can enable early identification of the alcohol use disorder and to improve the management of this problem in the hospital.

\section{Disciplines}

Medicine and Health Sciences

\section{Publication Details}

Qian, S., Irani, M., Brighton, R., Yeo, W., Reid, D., Sinclair, B., Bresnahan, S., Lynch, P., Feng, X. \& Yu, P. (2019). Investigating the management of alcohol-related presentations in an Australian teaching hospital.

Drug and Alcohol Review, 38 (2), 190-197.

\section{Authors}

Siyu Qian, Mudar Irani, Renee M. Brighton, Wilfred W. Yeo, David Reid, Barbara L. Sinclair, Susan Bresnahan, Peter Lynch, Xiaoqi Feng, and Ping Yu 
Title: Investigating the management of alcohol-related presentations in an Australian teaching hospital

Short running title: Alcohol-related presentations in a hospital

\begin{tabular}{|c|c|c|c|}
\hline Order & Name & $\begin{array}{l}\text { Highest academic } \\
\text { qualification }\end{array}$ & Job position and affiliation \\
\hline 1 & *Siyu Qian & $\mathrm{PhD}$ & $\begin{array}{l}\text { Research Associate } \\
\text { Centre for IT-enabled Transformation, School of } \\
\text { Computing and Information Technology, Faculty of } \\
\text { Engineering and Information Sciences, University of } \\
\text { Wollongong } \\
\text { Honorary Research Associate } \\
\text { Illawarra and Shoalhaven Local Health District } \\
\text { Illawarra Health and Medical Research Institute, University } \\
\text { of Wollongong, Wollongong, NSW, Australia }\end{array}$ \\
\hline 2 & *Mudar Irani & MBBS & $\begin{array}{l}\text { Advanced Trainee } \\
\text { Division of Medicine, Wollongong Hospital, Illawarra } \\
\text { Shoalhaven Local Health District }\end{array}$ \\
\hline 3 & $\begin{array}{l}\text { Renee } \\
\text { Brighton }\end{array}$ & $\mathrm{PhD}$ & $\begin{array}{l}\text { Senior Lecturer } \\
\text { School of Nursing, Faculty of Science, Medicine and } \\
\text { Health, University of Wollongong }\end{array}$ \\
\hline 4 & Wilfred Yeo & MD & $\begin{array}{l}\text { Professor of Medicine and Clinical Pharmacology } \\
\text { School of Medicine, Faculty of Science, Medicine and } \\
\text { Health, University of Wollongong; } \\
\text { Division of Medicine, Wollongong Hospital, Illawarra } \\
\text { Shoalhaven Local Health District } \\
\text { Illawarra Health and Medical Research Institute, University } \\
\text { of Wollongong, Wollongong, NSW, Australia }\end{array}$ \\
\hline 5 & David Reid & BSocSc (Hons) & $\begin{array}{l}\text { Director } \\
\text { Drug and Alcohol Service, Illawarra and Shoalhaven Local } \\
\text { Health District }\end{array}$ \\
\hline 6 & $\begin{array}{l}\text { Barbara } \\
\text { Sinclair }\end{array}$ & $\mathrm{PhD}$ & $\begin{array}{l}\text { Medical Director } \\
\text { Drug and Alcohol Service, Illawarra and Shoalhaven Local } \\
\text { Health District } \\
\text { Illawarra Health and Medical Research Institute, University } \\
\text { of Wollongong, Wollongong, NSW, Australia }\end{array}$ \\
\hline 7 & $\begin{array}{l}\text { Susan } \\
\text { Bresnahan }\end{array}$ & $\mathrm{BA}, \mathrm{BSc}$ & $\begin{array}{l}\text { Manager of Nursing Services } \\
\text { Drug and Alcohol Service, Illawarra and Shoalhaven Local } \\
\text { Health District }\end{array}$ \\
\hline 8 & Peter Lynch & BNurse & $\begin{array}{l}\text { Clinical Nurse Specialist, Consultation Liaison } \\
\text { Drug and Alcohol Service, Illawarra and Shoalhaven Local }\end{array}$ \\
\hline
\end{tabular}




\begin{tabular}{|l|l|l|l|}
\hline & & & Health District \\
\hline 9 & Xiaoqi Feng & PhD & $\begin{array}{l}\text { Director, Associate Professor } \\
\text { Population Wellbeing and Environment Research Lab } \\
\text { (PowerLab), School of Health and Society, Faculty of } \\
\text { Social Sciences, University of Wollongong, Australia }\end{array}$ \\
\hline 10 & $* *$ Ping Yu & PhD & $\begin{array}{l}\text { Illawarra Health and Medical Research Institute, University } \\
\text { of Wollongong, Wollongong, NSW, Australia }\end{array}$ \\
& & $\begin{array}{l}\text { Director, Associate Professor } \\
\text { Centre for IT-enabled Transformation, School of } \\
\text { Computing and Information Technology, Faculty of } \\
\text { Engineering and Information Sciences, University of } \\
\text { Wollongong }\end{array}$ \\
& $\begin{array}{l}\text { Honorary Research Associate } \\
\text { Illawarra and Shoalhaven Local Health District } \\
\text { Illawarra Health and Medical Research Institute, University } \\
\text { of Wollongong, Wollongong, NSW, Australia }\end{array}$ \\
\hline
\end{tabular}

1

$2 *$ These authors are joint first authors.

3

4

5

6

7

9

10 University of Wollongong, Wollongong NSW 2522 Australia

11 Email: ping@uow.edu.au; T + 61242215412

\section{Conflict of interest}

14 None to declare 
1 Title: Investigating the management of alcohol-related presentations in an Australian

2 teaching hospital

3

\section{$4 \quad$ Introduction and Aims}

5 Alcohol-related morbidity is estimated to range from $10 \%$ to $38 \%$ of the presentations to 6 hospital emergency departments. This study aims to investigate the actual management

7 process for alcohol-related presentations in a teaching hospital in Australia.

\section{Design and Methods}

9 Retrospective audit was conducted on the electronic medical records of 210 presentations 10 with a primary or secondary diagnosis of "alcohol use disorder" at discharge between 11 November 2016 and February 2017. Six key management steps were investigated: 12 identification of alcohol use disorder, documentation, thiamine, alcohol withdrawal assessment, benzodiazepine for alcohol withdrawal and referral to the drug and alcohol consultation liaison service.

\section{Results}

Of all the 210 presentations, $77.1 \%$ (162) were identified with alcohol use disorder in the initial assessments, $64.3 \%$ (135) were documented with alcohol use history, 49.5\% (104) were prescribed with thiamine, $48.1 \%$ (101) were assessed with the alcohol withdrawal scale, $41 \%$ (86) were prescribed with benzodiazepine for alcohol withdrawal and only $38.6 \%$ (81) were referred to the drug and alcohol consultation liaison service. Only 8.6\% (18) of the initial presentations were directly related to alcohol. These presentations had a higher completion rate in each of the six steps than those $(91.4 \%, 192)$ not directly related to alcohol. Only $6.2 \%$ (13) were formally screened for alcohol use.

\section{Discussion and Conclusions}

The findings suggest a need to improve the alcohol management practice in the hospital. Routine use of an alcohol screening tool can enable early identification of the alcohol use disorder and to improve the management of this problem in the hospital.

Keywords: alcohol use disorder, screen, management process, emergency departments, hospitals 
2 Alcohol is one of the top five risk factors for disease and disability that caused 3.3 million deaths annually $[1,2]$. In Australia, alcohol caused more than 5,500 deaths and 150,000

4 hospitalisations in 2010 [3].

5 With Emergency Department (ED) as the first "port of call" for many hospitalised patients, it 6 is estimated that $10 \%$ to $38 \%$ of the ED presentations are alcohol-related [4-6]. An Australian 7 study reported that $27 \%$ of ED patients used alcohol in the 24 hours prior to presentation [7]. 8 Sadly this type of presentation is often unidentified [8]. As alcohol withdrawal and its complications such as seizures may occur 6 hours after the last drink [9], failure in identification of alcohol use disorder (AUD) can lead to unexpected acute alcohol withdrawal. This can further complicate emergency assessment and diagnosis, causing harm to patients [10].

Early identification of AUD is essential for the medical staff to determine optimal clinical management of the patients [11]. An effective way is to use an alcohol screening tool to identify and assess whether alcohol is harming a person's health or is likely to cause harm in the future. Although there are validated, formal alcohol screening tools available such as Alcohol Use Disorders Identification Test (AUDIT) [12], the Cut-down, Annoyed, Guilt, Eye-opener (CAGE) [13] and the Paddington Alcohol Test (PAT) [14], the use of these tools remains unsatisfactory in Australian hospitals [15]. This results in a significant proportion of patients with AUD unscreened or undiagnosed, exposing them to the risk of developing alcohol withdrawal symptoms or complications. A recent Australian study evaluated the effectiveness of a routine screening and triage tool for alcohol withdrawal syndrome [16]. The study specifically measured the completion rate of identification of alcohol withdrawal syndrome, documentation of alcohol use and appropriate withdrawal management before and after the intervention. It found that after the use of the tool, there was a significant increase in the rate of documentation of alcohol use from $35.4 \%$ pre-intervention to $55.2 \%$ postintervention. The rate of appropriate management also increased significantly from $31.8 \%$ to $80 \%[16]$.

When AUD is suspected, assessment and documentation of alcohol use history should be conducted. This includes information such as duration, quantity, pattern of use, previous attempts to cut down alcohol intake or psychosocial impact [17, 18]. Research on 
1 documentation of alcohol use is sparse and is not specific to patients with AUD. One study of 2 documentation pattern of alcohol use in electronic medical records (eMR) in primary care 3 found that although $56 \%$ of the eMR had quantitative documentation of alcohol use, only $426 \%$ had qualitative descriptions of this use [19]. Another similar study in hospital records

5 for cancer patients found that in $57 \%$ of the documentation of alcohol use history was poorly 6 described as social, occasional or moderate drinkers [20]. Therefore, there is a need to assess 7 the documentation of alcohol use history for patients with AUD.

8 Due to prolonged heavy alcohol consumption, patients with AUD suffer from thiamine deficiency [21]. Therefore, once identified, these patients should be provided with thiamine to prevent Wernicke's encephalopathy, an acute neurological syndrome caused by thiamine deficiency [21-23]. The earlier thiamine is started, the faster the patient will recover [24]. Route of thiamine administration can be oral or parenteral. A retrospective medical record audit study found that among 226 patients, 89\% (201) were prescribed with oral thiamine [25]. However, for patients at risk of alcohol withdrawal, only $4.5 \mathrm{mg}$ of thiamine can be absorbed orally from any dose over $30 \mathrm{mg}$ [26]; therefore, parenteral thiamine is the standard of care $[21,27]$.

To assess severity of alcohol withdrawal and to guide therapy appropriately, several validated scales can be used [9]. The Alcohol Withdrawal Scale (AWS) requires less reliance on patients' response by assessing four physiological indicators (pulse, body temperature, sweating and tremor) and five mental or psychopathological symptoms (agitation, anxiety, tactile disturbances, disorientation and hallucination) common to alcohol withdrawal [28]. According to the Clinical Institute Withdrawal Assessment for Alcohol scale in its revised version (CIWA-Ar), the severity of alcohol withdrawal should be estimated by observation with patient participation [9]. In case of lacking patient cooperation, other tools can be used, such as the Richmond Agitation-Sedation Scale which is generally applicable to intensive care patients $[9,29]$.

To prevent progression to a more severe withdrawal, benzodiazepine is recommended to be used early in the management of alcohol withdrawal [17]. Despite the fact that within the first two days of withdrawal, benzodiazepine reduces the incidence of seizures by up to $84 \%$ and prevent the development of delirium tremens [9], a previous study found that only $37 \%$ of 
1 patients with AUD were prescribed with benzodiazepine for alcohol withdrawal management $2[30]$.

3 To provide effective advice on inpatient withdrawal management, assess patients' readiness 4 to change alcohol consumption behaviour and assist them to meet their goal, it is 5 recommended that clinicians refer every patient with AUD to the hospital-based Drug and 6 Alcohol Consultation Liaison (DA-CL) specialist service [17]. However, it is found that in 7 practice, only $51 \%$ of the patients with AUD were referred to the specialist treatment services 8 including Drug and Alcohol Service [30] and only 27\% of ED staff provided these patients 9 with formal referral to the outpatient alcohol service [31].

10 With the above prior knowledge, this research aims to understand and identify gaps in the 11 actual management process of patients with AUD in a teaching hospital in Australia. 12 Specifically, six key steps in the management of patients with AUD in hospitals were 13 examined: identification of AUD, documentation of alcohol use history, thiamine use, alcohol 14 withdrawal assessment, benzodiazepine for treatment of alcohol withdrawal and referral to 15 the DA-CL service. 


\section{Methods}

\section{$2 \quad 2.1 \quad$ Study design}

3 The study was conducted in a teaching hospital in New South Wales, Australia. To allow the 4 inclusion of any alcohol-related presentations, the diagnosis-related group (DRG) "AUD" 5 acquired on discharge was used to identify these presentations. This umbrella term includes 6 both apparent alcohol induced symptoms e.g. intoxication, and complications e.g. alcoholic 7 pancreatitis, of which initial disclosure are more difficult. Three hundred and sixty-seven 8 consecutive patient presentations with a primary or secondary discharge diagnosis of AUD 9 between 15 November 2016 and 15 February 2017 were identified retrospectively.

Among these consecutive presentations, 210 (57.2\%) presentations incurred by 199 patients were randomly selected. These included patients who were triaged and assessed in the ED, those who were directly admitted to the hospital wards and inter-hospital transfers. The randomization was performed in the IBM SPSS Statistics. As no paper file was used in the study hospital, all the patient information was extracted from the eMR for this audit research.

Audit of one patient record requires 30-minute manual work by the advanced trainee who could only afford half a day per week for research. That totals up to 105 hours of work. Given this constraint, the sample size may seem small, however it accounts for $57.2 \%$ of the total population.

An investigation of hospital re-presentation, re-admission and attendance to the communitybased Drug and Alcohol Service was also conducted 17 months after patient discharge.

The project was approved by the hospital authority as meeting the requirements for quality assurance/audit and therefore it did not require consideration by the Human Research Ethics Committees.

\subsection{Development of the audit protocol for extraction of data variables from the medical records}

A collaborative, consensus-based, multi-disciplinary approach was used to complete this research. In total, 17 project meetings were held among the authors. Of these meetings, three were focus group discussions to develop a data extraction scheme in order to ensure that the 
extracted data can address our research aim. The first focus group discussion involved three clinician authors to develop an initial list of 16 data variables for extraction. The second focus group involved six clinicians and a researcher in epidemiology to review and expand the list to 21 variables. The third focus group involved five clinicians to further scrutinise the data variables and one more variable- "number of AWS observations in the first 24 hours after presentation"- was added. A coding scheme, including the variables and their values, was developed by data extractor 1 , then validated by six clinicians. For example, three possible values for the variable "thiamine administration" were parenteral thiamine, oral thiamine and no drug prescribed.

The 21 data variables were grouped into seven categories:

- Patient characteristics include eight variables: gender, age, length of stay, admission specialty, admission ward, triage code, presenting problem and postcode.

- Identification of AUD includes three variables: screening tool used to assess the severity of AUD, whether AUD was identified at ED triage and who (job role) identified and documented AUD.

- Documentation of alcohol use history includes one variable: who (job role) documented detailed history of AUD (e.g. duration, quantity, pattern of use, previous attempts to cut down alcohol intake and social impact).

- Thiamine includes one variable: thiamine administration. Thiamine assists with nutritional deficiencies associated with AUD which, if untreated, may lead to Wernicke's encephalopathy [23].

- AWS assessment includes six variables: whether AWS was started prior to or after the medical officer's assessment, where was AWS first started, time to start AWS from presentation, number of AWS observations in the first 24 hours after presentation, maximum AWS score and documented alcohol withdrawal complications.

- Benzodiazepine for alcohol withdrawal includes two variables: type of prescribed benzodiazepine and benzodiazepine regime for alcohol withdrawal. These two variables were used to examine the practice of prescribing benzodiazepine for withdrawal.

- Referral to the DA-CL service includes one variable: whether the patient was referred to the DA-CL service following the clinical guideline. 


\section{$1 \quad 2.3 \quad$ Inter-rater agreement}

2 Data extraction was manually conducted by two medical officers with six years and 20 3 months of hospital work experience, respectively. They have sufficient experience of using 4 and extracting information from the eMR. They independently extracted the same 160 data

5 points. A comparison of their records showed a Cohen's Kappa score of 0.96; therefore, 6 adequate agreement was achieved [32].

\section{$7 \quad 2.4 \quad$ Data cleaning and analysis}

8 To ensure data accuracy, nine data validation rules were developed as the criteria to be used 9 to detect inconsistencies, outliers and missing values in a large dataset [33]. Applying 10 validation rules is a well-recognised method for checking data accuracy. For example, if no 11 AWS was performed, then there should be no record of an AWS score. These rules were then 12 applied to validate the data. Of the 3,360 data points manually extracted, 24 errors $(0.7 \%)$ 13 were identified in 19 patients' records, and were corrected through mapping back to the 14 original eMR. Descriptive statistical analysis was conducted using SPSS version 21 (IBM 15 Corp, Armonk, NY, USA). 


\section{$2 \quad 3.1 \quad$ Patient characteristics}

3 The 210 presentations were made by 199 patients; 30.2\% (60) female and 69.8\% (139) male

4 (see Table 1). Their age ranged from 14 to 90 years old (mean, 50.6, 95\% confidence interval $5 \quad[\mathrm{CI}], 48.11,53.17)$. On average, a patient stayed in the hospital for 5.9 days (95\% CI, 4.82, 6 6.97).

7 It is noteworthy that $91.4 \%$ (192) of the 210 presentations had an initial presenting problem 8 not directly related to alcohol, e.g. abdominal pain, reflecting the difficulty of fully disclosing 9 alcohol-related morbidity at the initial presentation. Among all the 210 presentations, $34.2 \%$ 10 (72) were admitted by emergency medicine specialty in the short stay area. This is followed 11 by general medicine $(18.6 \%, 39)$, psychiatry $(9 \%, 19)$, general surgery $(8.1 \%, 17)$, gastroenterology $(6.7 \%, 14)$ and others $(23.3 \%, 49)$.

\subsection{Identification and management of patients with alcohol use disorder}

Overall, only $6.2 \%$ (13) of the 210 presentations were formally assessed by a Mental Health substance use form, as there was no formal alcohol screening tool in place. Figure 1 shows the percentage of patients with AUD in each of the six key management steps. Among all patient presentations, $77.1 \%$ (162) were identified with AUD in the initial contacts with medical staff such as ED medical officer, ED nurse or specialty medical officer. The percentage of patients in each key step decreased from $64.3 \%$ (135) with a documentation of alcohol use history, $49.5 \%$ (104) with thiamine prescribed, $48.1 \%$ (101) with AWS assessment to $41 \%$ (86) with a prescription of benzodiazepine for alcohol withdrawal.

Of the 210 presentations, $38.6 \%$ (81) were referred to the DA-CL service and $61.4 \%$ (129) were not. Compared with the non-referred group, the referred one had higher proportion of female (32.1\% [26/81] vs. $29.5 \%$ [38/129]), lower average age (46.5 vs. 52.7) and lower proportion of non-alcohol related presenting problems (85\% [69/81] vs. 95.3\% [123/129]).

Of the 129 non-referred presentations, $83.7 \%$ (108/129) received no referral or advice. Although 4.7\% (6/129) were advised to contact the Drug and Alcohol Service, no formal 
1 referral was made. The rest $6.2 \%$ (8/129) of the patients declined referral or were abstinent,

$23.9 \%(5 / 129)$ were deceased and 1.6\% (2/129) were discharged against medical advice.

3 Of the 210 presentations, $8.6 \%$ (18) had presenting problems directly related to alcohol.

4 These presentations had a higher completion rate of each of the six key steps than those with

5 initial presenting problems not directly related to alcohol.

$6 \quad$ 3.3 Management of patients who developed moderate or severe alcohol withdrawal symptoms or complications

8 The alcohol withdrawal scores showed that $27.6 \%$ (58) of all presentations developed 9 moderate or severe withdrawal, and/or withdrawal complications (i.e. seizures, delirium and 10 hallucinations). Table 2 shows that $15.5 \%$ of these 58 presentations did not have thiamine and $1120.7 \%$ received oral thiamine. In the first 24 hours since presentation, $24.1 \%$ of these did not 12 receive any AWS assessment and $44.8 \%$ received one to four assessments. Regarding benzodiazepine regimes, only $1.7 \%$ were on loading dose, $34.5 \%$ were on symptom-triggered sedation and $31 \%$ did not have any prescription of benzodiazepine for withdrawal.

\subsection{Hospital re-presentation and re-admission}

As five patients were deceased in the index presentation, 194 patients were examined for their re-presentation, re-admission and attendance to the community-based Drug and Alcohol Service 17 months after discharge. Only 14\% (27/194) of these patients attended the community-based Drug and Alcohol Service. 57\% (111/194) re-presented to the ED, with $31 \%$ (61/194) identified with AUD. 44\% (86/194) were re-admitted (including direct ward admission) into the hospital, with 32\% (63/194) identified with AUD. These patients occupied 1,939 hospital days and 63\% $(1,216 / 1,939)$ of these days were alcohol-related. 


\section{$4 \quad$ Discussion}

2 This study investigated the practice of identification and management of patients with AUD 3 in an Australian teaching hospital. Medical records of 210 patient presentations with a 4 primary or secondary diagnosis of AUD were audited. The results showed that more than $590 \%$ of the presentations were not screened with a formal screening tool. Despite the well6 established evidence that early identification can inform optimal clinical management of 7 alcohol-related morbidity [11], our study showed that more than a fifth of the presentations were not identified with AUD in the initial assessment by the triage nurse, ED medical officer, specialty medical officer or ward nurse. Approximately a third of these presentations did not have documentation of alcohol use history. More than half of them did not have thiamine, AWS assessment and benzodiazepine for alcohol withdrawal. More than $60 \%$ were not referred to the DA-CL service.

Our audit found that alcohol screening was conducted for only $6 \%$ of the presentations, similar with what was found in a previous study that was also conducted in Australian hospitals [31]. It was also found that $23 \%$ of the presentations were not identified with AUD in the initial contact with medical staff, lower than the $30 \%$ found in a study conducted in an Australian trauma setting [15]. Identification of AUD and providing brief advice is a costeffective method to reduce alcohol-related morbidity in EDs [34]. Therefore, almost two thirds of 147 EDs surveyed in UK routinely screen patients' alcohol consumption [35]. Because there is strong evidence of a positive impact of screening on the subsequent management of AUD [36], there is a need to formally include an alcohol screening tool in the routine assessment in the hospital.

According to the local clinical guideline, AWS needs to be conducted second hourly in the first 12 hours and four to six hourly for the following 48 hours (Figure S1), which indicates that at least eight AWS observations should be recorded. Even this number might be an underestimate, our study found a lower number- only one to four AWS observations were recorded for most patients who exhibited moderate or severe withdrawal or developed withdrawal complications.

Thiamine is commonly prescribed to treat patients with alcohol withdrawal. It assists with nutritional deficiencies associated with AUD, which, if left untreated, can lead to Wernicke's encephalopathy [23]. However, for the 58 patients who suffered from moderate or severe 
1 withdrawal or developed withdrawal complications, $16 \%$ were not prescribed with thiamine and $21 \%$ of them received oral thiamine even though parenteral thiamine is recommended as the optimal delivery method [27].

4 Our study reveals that there are three benzodiazepine regimes used for treating alcohol 5 withdrawal: loading dose, fixed dose and symptom-triggered sedation. Loading dose regime 6 uses high doses of longer-acting benzodiazepine at the commencement of treatment with no 7 further tapering, to reduce withdrawal-related complications and symptomatology; whereas 8 with fixed dose regime, benzodiazepine is administered at regular intervals, and tapered down 9 over few days [17]. The symptom-triggered sedation regime can result in under-treatment by inexperienced staff who may not perform close monitoring of patient response. Because of this, our local guideline recommends using either the fixed or loading regimes (see Figure S2). Contradictory to this guideline, our study found that among the patients who developed moderate or severe alcohol withdrawal symptoms or complications, only $2 \%$ of them were on a loading dose regime. More than one third of them were sub-optimally prescribed the symptom-triggered benzodiazepine. Unexpectedly, more than $30 \%$ of the 210 patients did not receive any benzodiazepine.

17 According to the local clinical guideline, all of the patients who were diagnosed with AUD should be referred to the hospital DA-CL service. However, in reality, more than $60 \%$ of these patients were not referred, missing the opportunity to optimise care and provide relevant education to these patients [37]. 


\section{$1 \quad 5 \quad$ Limitation}

2 There is a potential under-reporting of AUD in the eMR because the study scope and 3 resource limitation did not allow the assessment of the completeness of the eMR in the study 4 hospital. However, the number of referrals to the DA-CL was validated by comparing the 5 data extracted from the eMR and the referral list kept by the DA-CL. The comparison found 6 that 22 referrals recorded by the DA-CL were not actually documented in the eMR. These 22 7 referrals were then added to the audit results.

8 The methodology of retrospective audit of eMR was also limited by the completeness and 9 accuracy of the records at the data entry stage. The number of AWS recordings may be under-estimated if the action was taken but was not documented in the eMR by the clinicians.

11 The results may also be affected by the spectrum of alcohol-related morbidity that was 12 manifested in the patient population and the clinical judgment used by the two medical 13 officers who extracted data to determine if a specified management step was implemented or 14 not. 


\section{Conclusion}

2 This study identified gaps in the management of patients with AUD. It identified a need to 3 routinely use an alcohol screening tool to screen patients at the initial presentation and to 4 improve alcohol management of patients with AUD in the hospital. Future research is 5 required to investigate why some patients with AUD were not referred to the DA-CL service 6 and how to improve the management of these patients across the continuum of care. 


\section{Acknowledgement}

2 This project is funded by the Global Challenges Program, the University of Wollongong, 3 with matching fund from the Drug and Alcohol Service, Illawarra \& Shoalhaven Local 4 Health District. It also received funding from the Illawarra Health \& Medical Research 5 Institute. Ms Eleanor Woodward is acknowledged for extracting data from the eMR. 
2 [1] Lim SS, Vos T, Flaxman AD, Danaei G, Shibuya K, Adair-Rohani H, AlMazroa MA, Amann M, Anderson HR, and Andrews KG. A comparative risk assessment of burden of disease and injury attributable to 67 risk factors and risk factor clusters in 21 regions, 1990-2010: A systematic analysis for the global burden of disease study 2010. Lancet 2012; 380(9859): 2224-60.

[2] World Health Organization, Global status report on alcohol and health 2014. 2014, World Health Organization: Geneva, Switzerland.

[3] Gao C and Ogeil R, Alcohol's burden of disease in Australia. 2014, FARE and VicHealth in collaboration with Turning Point: Canberra.

[4] Egerton-Warburton D, Gosbell A, Wadsworth A, Fatovich DM, and Richardson DB. Survey of alcohol-related presentations to Australasian emergency departments. The Medical Journal of Australia 2014; 201(10): 584-7.

[5] Egerton-Warburton D, Gosbell A, Moore K, Wadsworth A, Richardson D, and Fatovich DM. Alcohol-related harm in emergency departments: A prospective, multi-centre study. Addiction 2018; 113(4): 623-32.

[6] Ferreira JA, Wieruszewski PM, Cunningham DW, Davidson KE, and Weisberg SF. Approach to the complicated alcohol withdrawal patient. J Intensive Care Med 2017; 32(1): 3-14.

[7] Butler K, Reeve R, Arora S, Viney R, Goodall S, Gool K, and Burns L. The hidden costs of drug and alcohol use in hospital emergency departments. Drug Alcohol Rev 2016; 35(3): 359-66.

[8] Butler K, Reeve R, Viney R, and Burns L. Estimating prevalence of drug and alcohol presentations to hospital emergency departments in NSW, Australia: Impact of hospital consultation liaison services. Public Health Res Pract 2016; 26(4): e2641642e.

[9] Jesse S, Bråthen G, Ferrara M, Keindl M, Ben-Menachem E, Tanasescu R, Brodtkorb E, Hillbom M, Leone $\mathrm{M}$, and Ludolph A. Alcohol withdrawal syndrome: 
Mechanisms, manifestations, and management. Acta Neurol Scand 2017; 135(1): 416.

[10] Center for Substance Abuse Treatment, Alcohol and other drug screening of hospitalized trauma patients. 1995, Rockville (MD): Substance Abuse and Mental Health Services Administration (US).

[11] Yanta J, Swartzentruber G, and Pizon A. Alcohol withdrawal syndrome: Improving outcomes through early identification and aggressive treatment strategies. Emerg Med Pract 2015; 17(6): 1-18.

[12] Saunders JB, Aasland OG, Babor TF, De la Fuente JR, and Grant M. Development of the alcohol use disorders identification test (audit): Who collaborative project on early detection of persons with harmful alcohol consumption-ii. Addiction 1993; 88(6): 791-804.

[13] Ewing JA. Detecting alcoholism: The cage questionnaire. JAMA 1984; 252(14): 1905-7.

[14] Smith S, Touquet R, Wright S, and Gupta ND. Detection of alcohol misusing patients in accident and emergency departments: The paddington alcohol test (pat). J Accid Emerg Med 1996; 13(5): 308-12.

[15] Browne AL, Newton M, Gope M, Schug SA, Wood F, and Allsop S. Screening for harmful alcohol use in Australian trauma settings. Injury 2013; 44(1): 110-7.

[16] Lappin JM, Ayub MH, Rogers D, Morgan M, Kanyamibwa JY, and Shakeshaft A. Routine screening and related interventions significantly improve the effectiveness of emergency department detection and management of alcohol withdrawal syndrome. Emerg Med Australas 2018.

[17] Mental Health and Drug and Alcohol Office, Drug and alcohol withdrawal clinical practice guidelines- NSW. NSW Department of Health, Editor. 2008, NSW Department of Health: Sydney.

[18] Friedmann PD. Alcohol use in adults. N Engl J Med 2013; 368(4): 365-73.

[19] Torti J, Duerksen K, Forst B, Salvalaggio G, Jackson D, and Manca D. Documenting alcohol use in primary care in Alberta. Can Fam Physician 2013; 59(10): 1128. 
1 [20] Polednak AP. Documentation of alcohol use in hospital records of newly diagnosed cancer patients: A population-based study. Am J Drug Alcohol Abuse 2007; 33(3): 403-9.

[21] McKeon A, Frye MA, and Delanty N. The alcohol withdrawal syndrome. J Neurol Neurosurg Psychiatry 2008; 79(8): 854-62.

[22] Kattimani S and Bharadwaj B. Clinical management of alcohol withdrawal: A systematic review. Industrial psychiatry journal 2013; 22(2): 100.

[23] Long D, Long B, and Koyfman A. The emergency medicine management of severe alcohol withdrawal. Am J Emerg Med 2017; 35(7): 1005-11.

[24] Talbot PA. Timing of efficacy of thiamine in wernicke's disease in alcoholics at risk. J Correct Health Care 2011; 17(1): 46-50.

[25] Linder LM, Robert S, Mullinax K, and Hayes G. Thiamine prescribing and wernicke's encephalopathy risk factors in patients with alcohol use disorders at a psychiatric hospital. Journal of Psychiatric Practice 2018; 24(5): 317-22.

[26] Thomson AD and Marshall EJ. The treatment of patients at risk of developing wernicke's encephalopathy in the community. Alcohol Alcohol 2005; 41(2): 159-67.

[27] Frank LL. Thiamin in clinical practice. JPEN J Parenter Enteral Nutr 2015; 39(5): 503-20.

[28] Haber P, Lintzeris N, Proude E, and Lopatko O, Guidelines for the treatment of alcohol problems, Australian Government Department of Health and Ageing, Editor. 2009, Australian Government Department of Health and Ageing: Sydney.

[29] Varndell W, Elliott D, and Fry M. The validity, reliability, responsiveness and applicability of observation sedation-scoring instruments for use with adult patients in the emergency department: A systematic literature review. Australas Emerg Nurs J 2015; 18(1): 1-23.

[30] O'Regan A, Cullen W, Hickey L, Meagher D, and Hannigan A. Is problem alcohol use being detected and treated in irish general practice? BMC Fam Pract 2018; 19(1): 30. 
1 [31] Indig D, Copeland J, Conigrave KM, and Rotenko I. Attitudes and beliefs of emergency department staff regarding alcohol-related presentations. Int Emerg Nurs 2009; 17(1): 23-30.

[32] Landis JR and Koch GG. The measurement of observer agreement for categorical data. Biometrics 1977; 33(1): 159-74.

[33] Van den Broeck J, Argeseanu Cunningham S, Eeckels R, and Herbst K. Data cleaning: Detecting, diagnosing, and editing data abnormalities. PLoS Med 2005; 2(10): e267.

[34] Schmidt CS, Schulte B, Seo HN, Kuhn S, O'donnell A, Kriston L, Verthein U, and Reimer J. Meta-analysis on the effectiveness of alcohol screening with brief interventions for patients in emergency care settings. Addiction 2016; 111(5): 783-94.

[35] Patton R and Green G. Alcohol identification and intervention in english emergency departments. Emerg Med J 2017; 35(2): 75-8.

[36] Jones LA. Systematic review of alcohol screening tools for use in the emergency department. Emerg Med J 2010; 28(3): 182-91.

[37] Walton MA, Goldstein AL, Chermack ST, Mccammon RJ, Cunningham RM, Barry KL, and Blow FC. Brief alcohol intervention in the emergency department: Moderators of effectiveness. J Stud Alcohol Drugs 2008; 69(4): 550-60. 


\section{$1 \quad 8$ Tables}

2 Table 1. Characteristics of patient presentations.

\begin{tabular}{|c|c|c|}
\hline Data variable & Data value & $\mathbf{N}(\%)$ \\
\hline \multirow{2}{*}{$\begin{array}{l}\text { Gender } \\
(\mathrm{N}=199)\end{array}$} & Female & $60(30.2)$ \\
\hline & Male & $139(69.8)$ \\
\hline \multirow{8}{*}{$\begin{array}{l}\text { Age group } \\
(\mathbf{N}=199)\end{array}$} & $<20$ & $10(5)$ \\
\hline & $20-29$ & $23(11.6)$ \\
\hline & $30-39$ & $21(10.6)$ \\
\hline & $40-49$ & $35(17.6)$ \\
\hline & $50-59$ & $42(21.1)$ \\
\hline & $60-69$ & $41(20.6)$ \\
\hline & $70-79$ & $18(9)$ \\
\hline & $80-90$ & $9(4.5)$ \\
\hline \multirow{5}{*}{$\begin{array}{l}\text { Triage code } \\
(\mathrm{N}=\mathbf{2 1 0})\end{array}$} & 1. Immediately life threatening condition (has to be seen immediately) & $8(3.8)$ \\
\hline & 2. Imminently life threatening condition (has to be seen in 10 minutes) & $38(18.1)$ \\
\hline & 3. Potentially life threatening condition (has to be seen in 30 minutes) & $100(47.6)$ \\
\hline & 4. Potentially serious (has to be seen in 60 minutes) & $37(17.6)$ \\
\hline & The patient was directly admitted to ward and was not seen by ED triage & $27(12.9)$ \\
\hline \multirow{2}{*}{$\begin{array}{l}\text { Presenting problem } \\
(\mathrm{N}=\mathbf{2 1 0})\end{array}$} & Non-alcohol related & $192(91.4)$ \\
\hline & Alcohol-related & $18(8.6)$ \\
\hline
\end{tabular}


1 Table 2. Management of patients who exhibited moderate or severe withdrawal or 2 developed withdrawal complications.

\begin{tabular}{|c|c|c|c|}
\hline Data variable & Data value & $\begin{array}{l}\text { Number of } \\
\text { presentations }\end{array}$ & $\begin{array}{l}\% \\
(\mathrm{~N}=58)\end{array}$ \\
\hline \multirow{3}{*}{$\begin{array}{l}\text { Thiamine } \\
\text { administration }\end{array}$} & Parenteral thiamine & 37 & 63.8 \\
\hline & Oral thiamine & 12 & 20.7 \\
\hline & No drug prescribed & 9 & 15.5 \\
\hline \multirow{6}{*}{$\begin{array}{l}\text { Where was AWS } \\
\text { first started }\end{array}$} & ED until discharge & 25 & 43.1 \\
\hline & ED and continued on ward & 1 & 1.7 \\
\hline & ED but discontinued on ward & 5 & 8.6 \\
\hline & Ward (patients admitted through ED) & 8 & 13.8 \\
\hline & Direct ward admission & 5 & 8.6 \\
\hline & No AWS assessment was performed & 14 & 24.1 \\
\hline \multirow{5}{*}{$\begin{array}{l}\text { Time to commence } \\
\text { AWS since triage or } \\
\text { ward admission }\end{array}$} & 0 to 6 hours & 22 & 37.9 \\
\hline & 6 to 12 hours & 12 & 20.7 \\
\hline & 12 to 24 hours & 5 & 8.6 \\
\hline & After 24 hours & 5 & 8.6 \\
\hline & No AWS assessment was performed & 14 & 24.1 \\
\hline \multirow{4}{*}{$\begin{array}{l}\text { Number of AWS } \\
\text { observations in the } \\
\text { first } 24 \text { hours after } \\
\text { presentation }\end{array}$} & 1 to 4 times & 26 & 44.8 \\
\hline & 5 to 7 times & 9 & 15.5 \\
\hline & 8 to 10 times & 4 & 6.9 \\
\hline & None & 19 & 32.8 \\
\hline \multirow{4}{*}{$\begin{array}{l}\text { Type of prescribed } \\
\text { benzodiazepine for } \\
\text { alcohol withdrawal }\end{array}$} & Diazepam & 31 & 53.4 \\
\hline & Oxazepam & 5 & 8.6 \\
\hline & Diazepam and oxazepam & 4 & 6.9 \\
\hline & No drug prescribed & 18 & 31 \\
\hline \multirow{5}{*}{$\begin{array}{l}\text { Benzodiazepine } \\
\text { regime for alcohol } \\
\text { withdrawal }\end{array}$} & Loading & 1 & 1.7 \\
\hline & Fixed & 15 & 25.9 \\
\hline & Symptom-triggered sedation & 20 & 34.5 \\
\hline & Other & 4 & 6.9 \\
\hline & No drug prescribed & 18 & 31 \\
\hline \multirow{6}{*}{$\begin{array}{l}\text { Referral to the DA- } \\
\text { CL service }\end{array}$} & Yes & 26 & 44.8 \\
\hline & No referral or advice & 23 & 39.7 \\
\hline & $\begin{array}{l}\text { No referral but patient was advised to contact the DA-CL } \\
\text { service }\end{array}$ & 2 & 3.4 \\
\hline & No referral because of patient death & 4 & 6.9 \\
\hline & $\begin{array}{l}\text { No referral because the patient was discharged against } \\
\text { medical advice }\end{array}$ & 1 & 1.7 \\
\hline & Patient declined referral or patient abstinent & 2 & 3.4 \\
\hline
\end{tabular}

DA-CL: Drug and Alcohol Consultation Liaison 


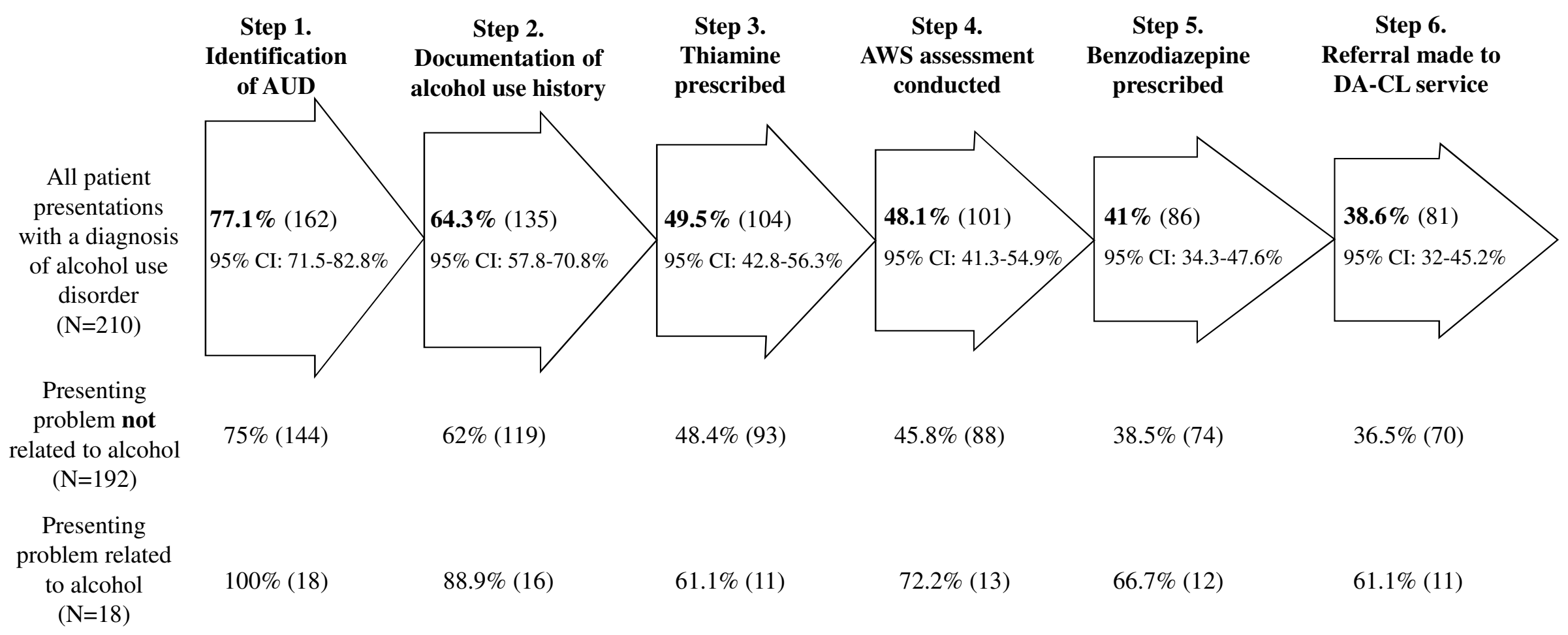

AUD: alcohol use disorder; AWS: Alcohol withdrawal scale; DA-CL: Drug and Alcohol Consultation Liaison

Figure 1. Percentage of patients with alcohol use disorder in each of the six key management steps. 